\title{
A GIS based methodology for Alta Murgia Park fire risk assessment
}

\author{
L. Pirone ${ }^{1}$, F. Intini ${ }^{1,2} \&$ V. D'Agostino ${ }^{3}$ \\ ${ }^{1} S M A$ SpA, Via Zona Industriale - C.P. 154 e 155, 70015 Noci (BA), Italy \\ ${ }^{2}$ GAP srl-Physics Department, University of Bari, Via Amendola 173, \\ 70126 Bari, Italy \\ ${ }^{3}$ Tecnopolis CSATA, 70010 Valenzano, Bari, Italy
}

\begin{abstract}
In this paper we present a new approach for evaluating forest fire static risk. This new methodology, based on cartographic data integration, has been applied to Alta Murgia National Park, located in the South East of Italy, to identify fire more vulnerable areas. The static risk resulted strongly dependent on factors which are constant or which are varying very slowly with time, such as morphological factors (exposition, inclination), environmental static factors (soil use and vegetation coverage) and human factors (urban areas extension, road network, restoring activity centres, fire recurrence during the past five years at least). Moreover, on the short time, fire risk (particularly fire start and development) results strictly related to different factors such as vegetation factors (types and density, maintenance management rules), orographic factors (altitude, sides exposition and inclination, insulation), meteorological factors (air temperature, air humidity, wind velocity and direction, last ten days cumulated rain). The methodology we used is based on a step by step procedure for the calculation of any of the factors mentioned above. Data processing has been realized in a GIS (Arcview 3.2) environment using overlay procedures. The result is a chart representing five levels of fire risk (static) with a resolution of 30 $\mathrm{m}$. Significantly helpful resulted fuzzy logic applications for previous indicators integration. This kind of procedure, which allows remote sensing data as well as local measured data assimilation, gives to local authorities a highly versatile tool for fire risk localisation and for Alta Murgia Park resources optimal planning and management.
\end{abstract}

Keywords: fire risk, fuzzy logic, AHP, WLC, Alta Murgia Park. 


\section{Introduction}

Forest fires can be considered one of the main cause of environment degradation, contributing on a large scale to planetary changes (climate, etc.). The frequency of fires and the area travelled by the fire are likely to contribute significantly to the reduction of biodiversity. From 1994 to 2006, in Apulia region, occurred on average 333 fires/year, with an average size woodland travelled from the fire of around 2,000 ha and with an average area for each fire that is greater than 5 ha. Specifically, from 2000 to 2006 a total of 227 fires occurred in a limited protected area: the Alta Murgia National Park, which is located in the northwestern area of Apulia region. The total surface burned by these fires amounted to about 4920.32 ha, where on average each fire has burned 21.67 ha of vegetation. These data can be understood if we consider that agricultural and pastoral activities are widespread. The fragility of natural systems flows from the neighbourhood and often intermingling of natural areas with those production is pasture that cultivation. Agricultural practices such as burning stubble after harvesting of wheat or the burning of pastures to encourage the development of grass species, which currently find meaning only in the agro-pastoral tradition, are the main cause of fires. Therefore it can be concluded that human activities, often accidentally and sometimes negligence, can be identified as the primary source of fires. In order to evaluate the static fire risk for the park, is essential to pertain a new methodology that takes into account properly the human factor too. The risk may be understood as the union of two components: 1) the fuel with its susceptibility to fire (fire hazard), 2) all external factors (natural and anthropogenic) influencing the outbreak (fire ignition). The risk analysis allows to define an index, expressed by a mathematics that binds these different factors. The procedure applied in the present work allows not only to classify various levels of risk but moreover to estimate the potential contribution of each factor (San-Miguel-Ayanz [9]). This procedure makes use of a static risk index whose the factors determining the risk are characterized by a very slow variation over time (IRIS index). The aim of the present work was to implement a model based on a multi-criterial analysis, whose procedure allows to mark a goal and estimate it by means of the application of a decisional rule based on a plurality of criteria (Fig. 3). This evaluation has been performed in a GIS environment, by means of a technique of mapping overlay which allows one to assign a value to each criterion represented by each map.

\section{Area of study description}

The Alta Murgia Park broadens over an area of 68.077 ha and is divided into three zones: the first has an extension about of 21.000 ha, the second has an extension about of 45.000 ha and the third of 995 ha. It includes the territories of 13 municipalities: Altamura, Andria, Bitonto, Cassano delle Murge, Corato, Gravina in Puglia, Grumo Appula, Minervino Murge, Poggiorsini, Ruvo di Puglia, Santeramo, Spinazzola, Toritto, two mountain communities (Murgia of 


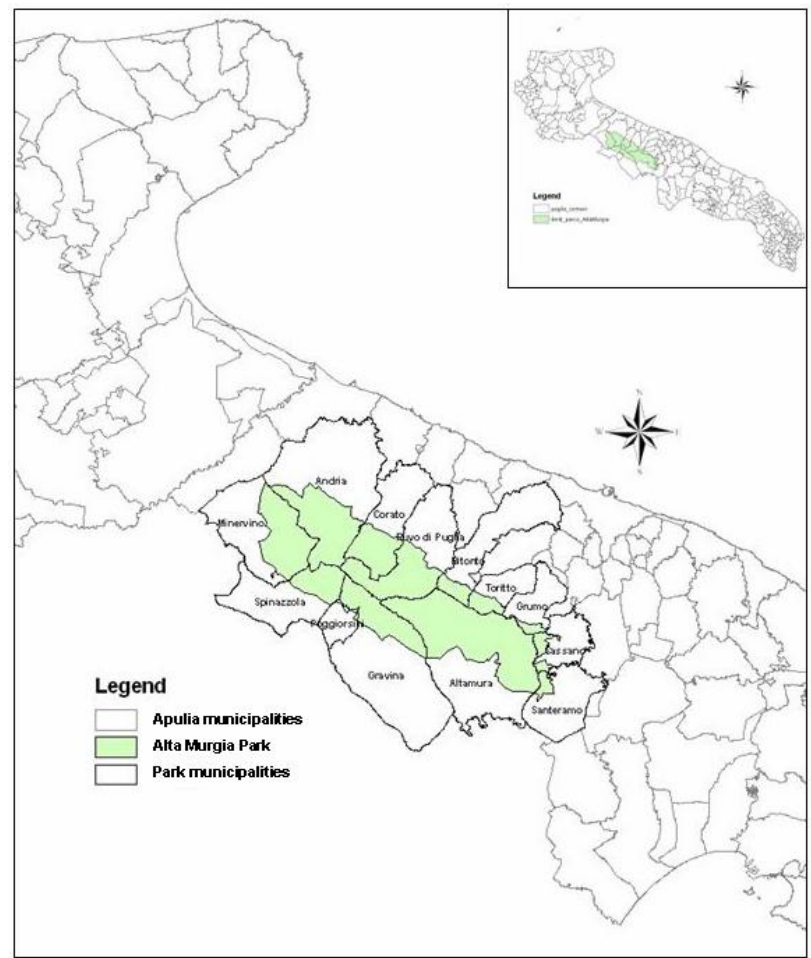

Figure 1: $\quad$ Alta Murgia Park area.

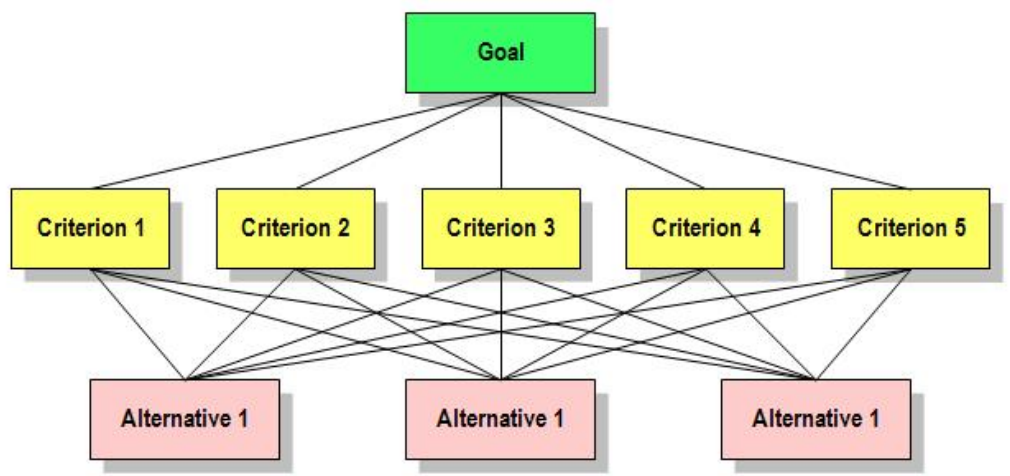

Figure 2: $\quad$ Multicriterial analysis scheme.

Barese Northwest and Murgia Barese South-East) and two Provinces (Bari and Barletta-Andria-Trani).

On a morphological point of view the Park presents a great mass of the Murgia limestone which was subject to a very long action of mechanical and 


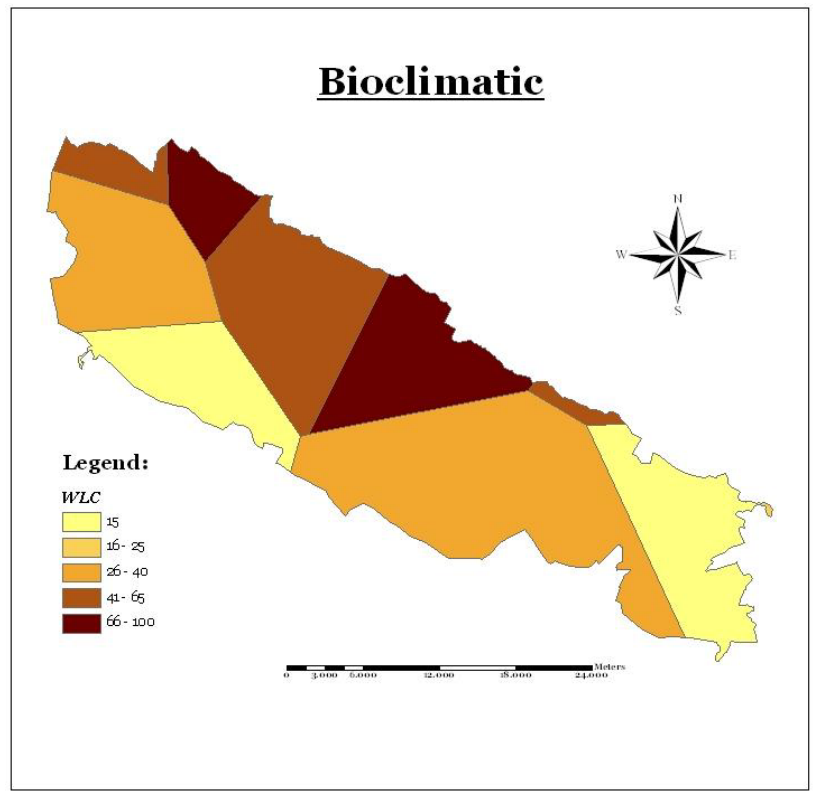

Figure 3: $\quad$ Bioclimatic map.

Table 1: $\quad$ Park extensions within each municipality.

\begin{tabular}{|c|c|c|c|}
\hline Municipality & Extension (ha) & Municipality & Extension (ha) \\
\hline Altamura & 12660 & Poggiorsini & 127,5 \\
\hline Andria & 12000 & Ruvo & 9949,5 \\
\hline Bitonto & 1959 & Santeramo & 864 \\
\hline Cassano & 3206 & Spinazzola & 3944 \\
\hline Gravina & 7587 & Toritto & 1923 \\
\hline Grumo & 627 & Corato & 5411 \\
\hline Minervino & 7481 & & \\
\hline
\end{tabular}

chemical erosion by wind and rainwater rich in carbon dioxide. These lasts have thus shaped forms giving rise to an exceptional repertoire of Karstification, the most common and widespread of which are karst basins. Typical of these areas are the dolines (pulo) as the pulo of Altamura, which is $550 \mathrm{~m}$ in diameter and $92 \mathrm{~m}$ deep, and little pulicchie of Gravina. The most evident consequence of Karstification is the almost total disappearance of a superficial hydrographs. The underground hydrographs is instead very developed. Due to the high permeability of soil, Alta Murgia serves as the training of the aquifer in the Province of Bari and is therefore subject to hydro geological bond.

\subsection{Vegetation types}

The most typical and widely used forestry species, within Alta Murgia Park, are Oak species for which the predominant forms of government are simple Coppice 
and a combination of Coppice with Sapling. The Oak species are: Quercus trojana Webb, Quercus ilex L., Quercus cerris L., Quercus coccifera L., Quercus pubescens Willd. and Quercus frainetto Ten.. Artificial origin plants, such as Pinus halepensis Mill., are also very popular within the Park. The pine forests are also made up of undergrowth Quercus ilex L., Pistacia lentiscus, Phillyrea angustifolia, Rhamnus alaternus. Interventions of reforestation with this kind of plants have started a process of territorial restoring which improved territory conditions.

\subsection{Climate}

The climate of the park is a sub-Mediterranean showing average annual temperatures of $17.5^{\circ} \mathrm{C}$ in proximity of Andria (lower locations and near the sea) and $14.4^{\circ} \mathrm{C}$ to Altamura (highest locations and farthest from the sea). The coldest month is January with average temperatures around $7^{\circ} \mathrm{C}$ and minimum temperatures often drop below freezing. The hottest month is in July or August depending on the vintages and localities, with average temperatures around $25^{\circ} \mathrm{C}$. Precipitations are concentrated in autumn-winter period with a maximum in November-December. The average annual values fluctuate between $578 \mathrm{~mm} /$ year into Altamura areas to about $700 \mathrm{~mm} /$ year near Santeramo. The snowfall are not present every year and focus above $500 \mathrm{~m}$ above sea level. The winds are more frequent from northern quadrants (mostly cold) than from west and south (mainly hot) directions, and they that give rise to local names: Serratina wind (cold and dry) in the north, accompanied by frost, and Favonio wind southern and south-west, hot and extremely dry. The result of this climate is the presence of two seasons in favour of vegetation, the spring and the autumn, spaced of two more critic seasons of rest. Particularly, the influence of summer aridity imposes a biological recovery for most species of herbaceous and determines a suspension growth for all fanerofite (perennials and woody plants).

\section{Methodology description}

The present work has been developed by Engineering, Development and Innovation Area of SMA SpA. SMA is the Italian leading company supporting the national system of Civil Defense for each activity pertaining the safety on the territory, focusing its attention to forest fire defense (Nacci et al. [6]).

A new approach for forest fire risk evaluating is based on the application of models applying particular decisional rules which, through the simulation of different scenarios, make user able to foresee the consequences of different territory planning choices. The application of decision support systems to this kind of activities results more efficient if it's realized by means of geographic informative systems (GIS) for their ability to process and manage a large amount and variety of territorial data. The decisions applied for the achievement of a target which, in our work is represented by the identification of higher static fire risk areas, are usually based on a plurality of objective elements, which are identifiable and measurable, called criteria. 
The multi-criteria analysis developed in a GIS environment, in particular, allows to employ the procedure of evaluation, having set a target, by overlaying thematic maps corresponding to different criteria. The criteria applied in the present work can be distinguished into two categories: discrete criteria and continuous criteria. The first category is characterized by attributes varying in a discontinuous manner; these are: vegetation, exposition, bioclimatic, road network. The second category is characterized by attributes varying continuously which, in the present work, are only represented by the slope. The representation of the criteria by means of GIS themes has requested the implementation of a series of thematic maps developed with the Arcview software and realized on the basis of data collected and tests conducted on the territory of study. To be able to assess the criteria we needed to carry out a normalisation which involves the allocation of weights to different territorial units elementary. This was achieved through the application of two different procedures based on the type of criteria. For the discrete criteria, the Analytic Hierarchy Process AHP (Saathy [10]) for multi-criteria analysis was applied. This procedure consists of a comparison in pairs between the various analyzed factors and is based on a hierarchical structure of the items covered by decision-making problem. For this reason AHP procedure needs a preliminary division of criteria into classes of appropriateness. This division has been relevant for discrete variables. As regards, however, the normalization of those criteria that vary in a continuous manner (slope), there is a difficulty of establishing a precise limit to assign a pixel to a class of appropriateness rather than to another, without run the risk of their choices questionable. The criteria that vary continuously are defined as fuzzy set as they have an objective difficulty of establishing clear rules on the basis of which assign a pixel to a class. In this case, therefore, for standardization of data is appropriate to use fuzzy logic. For the normalization of this kind of criteria we used the fuzzy set module of Idrisi32 software. In order to obtain the map of static risk we necessitated further cartographic processing consisting of the transformation in raster images of thematic vector maps representing different criteria. The size of pixels was established according to the study of the territory and the scale at which we carried out the analysis, so as not to encumber the subsequent calculation operations. Then, the final size of elementary territorial units (pixels) is $30 \times 30$ metres. The criteria normalization has been performed using a common scale between 0 and 100 (where the value " 0 " represents the worst condition and value " 100 " the most favourable to fire ignition). Once developed 5 layers of information about the level of fire risk, their weighing linear combination (WLC), performed through the MCE module of Idrisi32 software, allows to create the final map of Static fire risk related to Alta Murgia National Park area. This map shows: 1)Very low risk areas, 2) Low risk areas, 3) Medium risk areas, 4) High risk areas, 5) Very high risk areas.

\subsection{Climate policy}

Among the climate factors influencing on short and long time the fire risk, in the present work we considered the following two variables: temperature and rain. For the evaluation of the variable climate it has been used the Chart of Bioclimi, 
obtained by applying Rivas-Martinez index, based on the data collected over thirty years from 1974 to 2003 by the stations located within or in the neighbourhood of the park (Hydrographic Service of Apulia region). Limited to the territory of the Park Murgia, we found 6 different bioclimatic classes. The standardization of data has been conducted in accordance with the AHP procedure whose standard risk factors are shown in Figure 3.

\subsection{Slope}

The slope on the one hand facilitates the progress of the front of fire (ROS Rate Of Spread) forward to the highest areas, whose fuel is normally preheated and its condition is more favourable to combustion, on the other affects the risk of ignition by facilitating contact between the canopy and promoting the rolling of burnt elements to the bottom (Fig. 4). For the realization of the slope map we made use of DEM (Digital Elevation Model) of the Park.

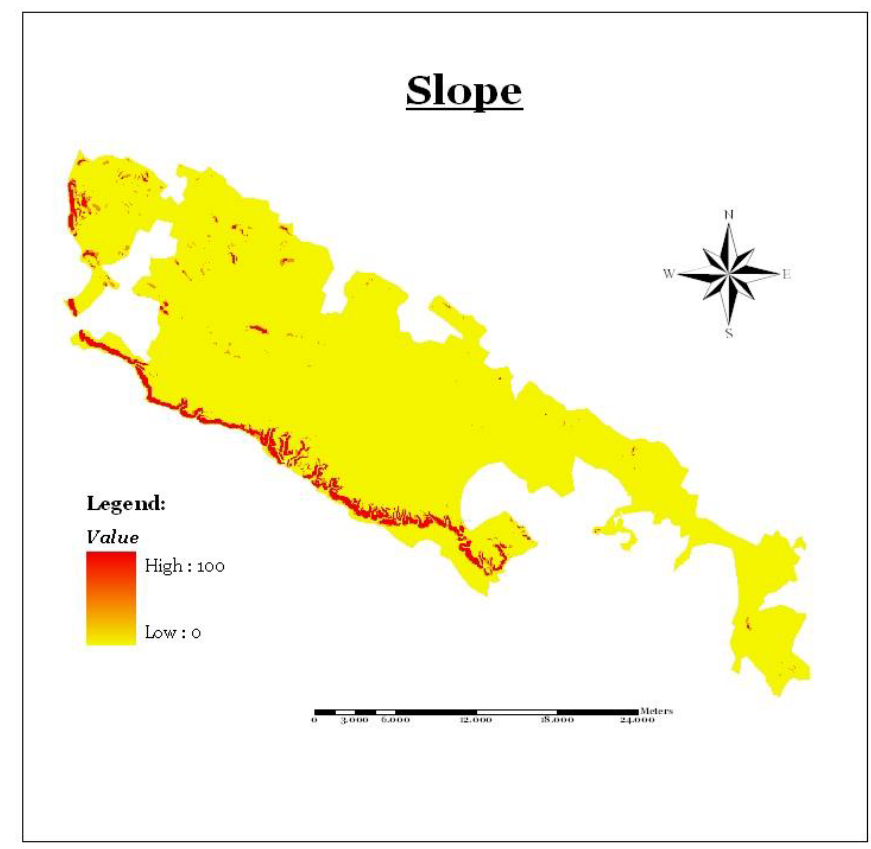

Figure 4: $\quad$ Slope map.

\subsection{Exposure}

The exposure is a factor that affects the water content of vegetation. This parameter determines the time of solar irradiation on the site and thereby affect the temperature and moisture content of the fuel. Generally southwest exposure leads to more radiation and promotes the loss of moisture from the vegetation. The higher the moisture content of the fuel and less vulnerable will be the same. 
For the realization of the exposure map we made use of DEM (Digital Elevation Model) of the Park. We identified 9 classes of exposure which were subjected to AHP procedure (Fig. 5).

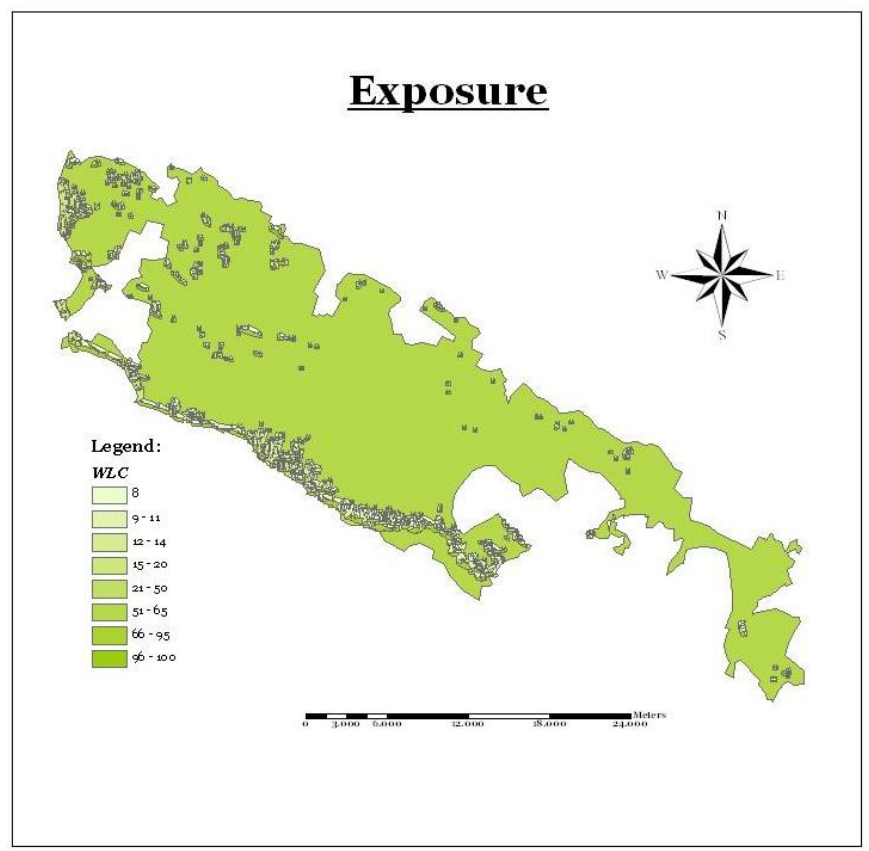

Figure 5: $\quad$ Exposure map.

\subsection{Vegetation}

The vegetation is the fuel and therefore it is the most important factor in determining the behaviour of fire and intensity of the flame front. In particular, in addition to topographical and climatic factors, the main parameters that favour the spread of fire are the load of fuel present in a given area and its physical and chemical characteristics. In the present work we made use of the official Vegetation chart realized by Alta Murgia Park administration. We identified 10 classes of fuel which were in turn subjected to AHP procedure (Fig. 6).

\subsection{Anthropic factor}

Many studies show that about $90 \%$ of fires are due to human factors. So, despite the importance assumed by this variable, many investigations relating to the evaluation of the risk of fire continue to neglect this aspect. This is due to the difficulty of correctly evaluate this component, characterized by factors difficult to predict and complex spatial representation. This problem was resolved through the definition of certain factors to be considered, taken from official maps and used in the definition of anthropic risk. These are: roads, urban and 


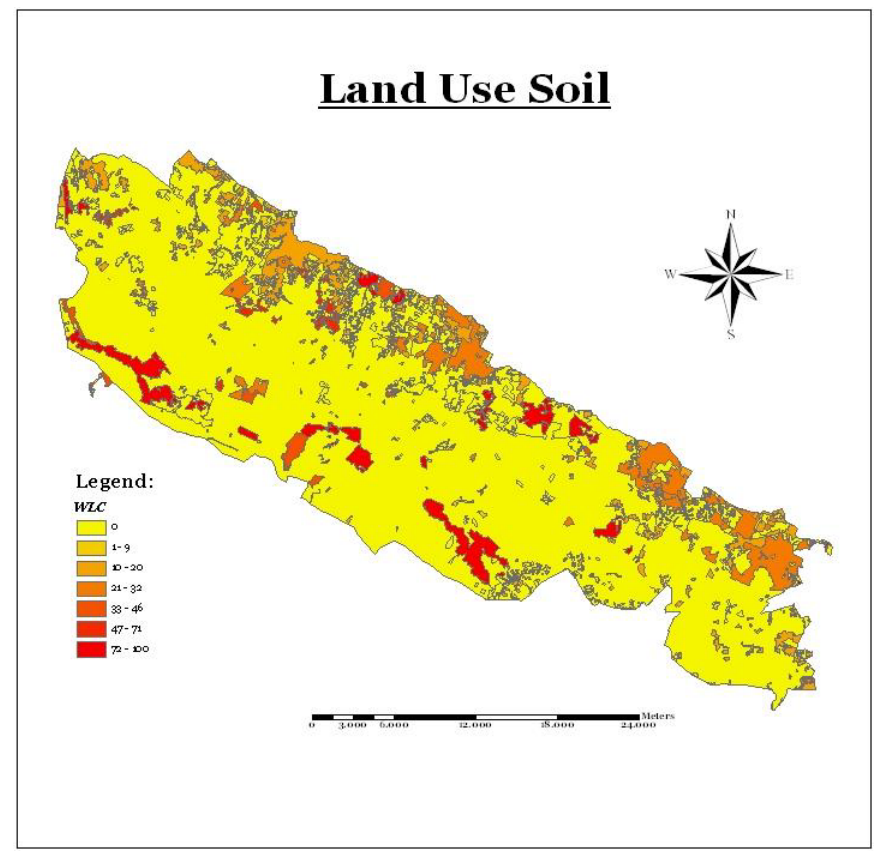

Figure 6: Land use map.

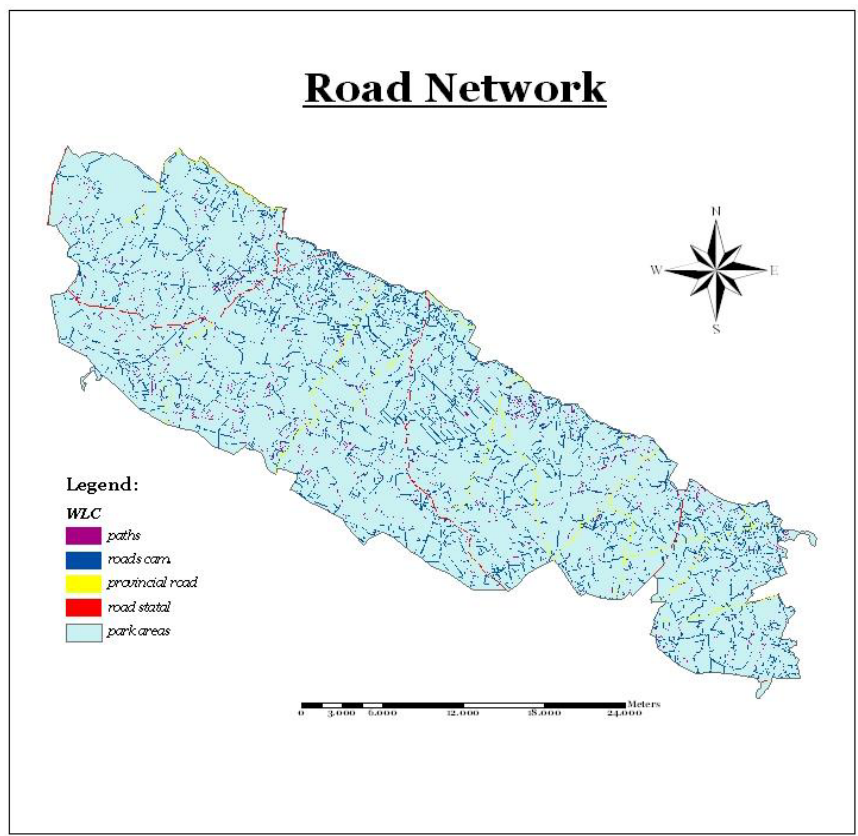

Figure 7: $\quad$ Road network map. 
points of ignition. In this work was considered only the factor of road networks, whereas the presence of roads makes more vulnerable the woods compared to human behaviour, since many fires develop its elements in the vicinity of roads, as shown by the analyses conducted by the CFS on points of ignition of fires. In the present work we made use of the official Road Network chart realized by Alta Murgia Park administration. We identified 4 classes of different types of roads (trails, trucks, provincial and state) who have been executed for buffers of 10 metres for trails, $20 \mathrm{~m}$ for trucks and for $25 \mathrm{~m}$ provincial roads and state. Each class has been weighed with AHP procedure (Fig. 7).

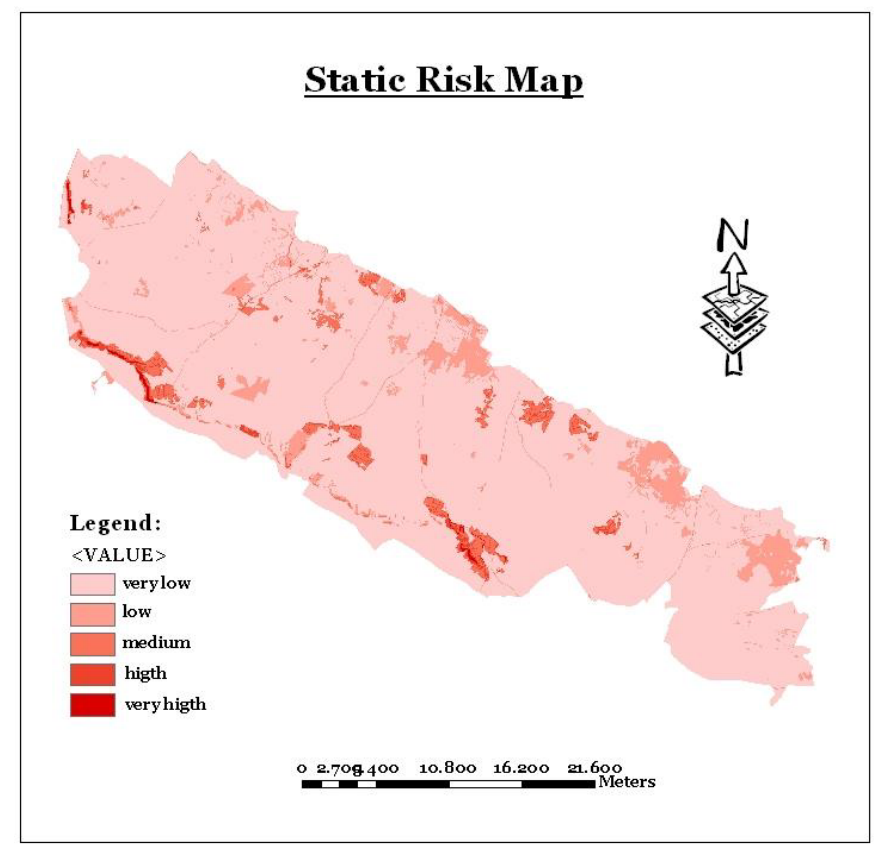

Figure 8: $\quad$ Static fire risk map.

\section{Results}

By analyzing the results obtained, it can be noted that the territory of the protected area is characterized by a predominance of low-risk areas $(39.6 \%$ of the total area of the park). We can identify approximately $24.3 \%$ of areas at very low risk, the high-risk areas are a total of $17.2 \%$, the high-risk areas are the $13.1 \%$ of the territory of the park, while a smaller part is represented by areas with very high risk, only $5.8 \%$. The localization of high-risk areas is strongly influenced by the high importance attached to climate and vegetation factors. The high-risk areas covered, in fact, within bands bio characterised by a high summer drought and summer temperatures average higher than the rest of the territory of the park. Moreover, in such areas, the vegetable stand is 
characterized by an expanded presence of pastures, forests hardwood to the prevalence of species termofite and mixed forests with prevalence of conifers particularly susceptible to fires, with areas characterized by a significant human presence. For this reason, the methodology multi criteria is the most appropriate as it includes several issues simultaneously. In addition, the possibility of applying fuzzy functions on territorial data type for continuous variable classification, offers a flexible instrument whose only difficulty is the choice of the function that best interprets this phenomenon. The application of systems to support decisions in combination with the use of GIS has proved a very powerful tool to carry out analysis on risk assessment fire.

\section{References}

[1] Di Fazio S., Modica G., Pulvirenti A. (2007), "Il rischio incendi boschivi nella pianificazione territoriale delle aree naturali protette in ambito mediterraneo. Il caso del parco dell'Etna", XXVI conf. italiana di scienze regionali;

[2] Ente Parco (2008), "Piano antincendio boschivo del Parco dell'Alta Murgia", documenti studi e ricerche;

[3] Eufirelab (2006) Deliverable D-08-05. Common methods for mapping the wildland fire danger. December 2006;

[4] Il Fuzzy pensiero - B. Kosko - Baldini \& Castoldi editori;

[5] Marinelli G. (2008), Tesi di ricerca in Ingegneria del Territorio e dell'Ambiente Agroforestale: "Criteri e metodi per l'individuazione e perimetrazioni delle aree protette";

[6] G. Nacci, F. Intini, G. Meuli, Optimization Developing security and ensuring development. A model for fire forest management. WILDFIRE 2007, 4th International Wildfire Conference, Siviglia, Spagna, 2007

[7] Regione Puglia (2003), "Piano Regionale di Previsione, Prevenzione e lotta attiva contro gli incendi boschivi 2004-2006", documenti studi e ricerche;

[8] Rivas-Martinez S. (1995) Bases para una nueva clasificacion bioclimatica de la Tierra. Folia Botanica Matritensis, 16;

[9] San-Miguel-Ayanz J. (2002), "Methodologies for the evaluation of forest fire risk: From long-term (static) to dynamic indices" - Atti del XXXIX Corso di Cultura in Ecologia, 2002;

[10] Saaty, T.L., The Analytic Hierarchy Process, McGraw Hill, New York, 1980;

[11] Saaty, T. L., 1994. "Fundamentals of Decision Making and Priority Theory with the Analytic Hierarchy Process" RWS Publications, Pittsburg; 